\title{
Effect of the Creatinine Excretion Rate Index, a Marker of Sarcopenia, on Prediction of Intracranial Hemorrhage in Patients With Advanced Heart Failure and a Continuous-Flow Left Ventricular Assist Device
}

\author{
Keiichiro Iwasaki, MD; Osamu Seguchi, MD, PhD; Shunsuke Murata, PhD; \\ Kunihiro Nishimura, MD, PhD; Koichi Yoshitake, MD; Nobuichiro Yagi, MD; \\ Yasumori Sujino, MD; Eiji Anegawa, MD; Hiroki Mochizuki, MD; Kensuke Kuroda, MD; \\ Seiko Nakajima, MD, PhD; Takuya Watanabe, MD, PhD; Masanobu Yanase, MD; \\ Satsuki Fukushima, MD, PhD; Tomoyuki Fujita, MD, PhD; Junjiro Kobayashi, MD, PhD; \\ Hiroshi Ito, MD, PhD; Norihide Fukushima, MD, PhD
}

\begin{abstract}
Background: Sarcopenia is characterized by progressive loss of skeletal muscle and has frequently been associated with poor clinical outcomes in patients with advanced heart failure (HF). The urinary creatinine excretion rate (CER) index is an easily measured marker of muscle mass, but its predictive capacity for mortality and cerebrovascular events has not been investigated in patients with a continuous-flow implantable left ventricular assist device (CF-iLVAD).
\end{abstract}

\begin{abstract}
Methods and Results: We retrospectively reviewed 147 patients (mean $[ \pm S D]$ age $43.7 \pm 12.5$ years, 106 male) who underwent CF-iLVAD implantation between April 2011 and June 2019. CER indices in 24-h urine samples before CF-iLVAD implantation were determined. Over a median follow-up of 2.3 years, there were $10(6.8 \%)$ deaths and $43(29.3 \%)$ cerebrovascular events. Patients were divided into 2 groups (low and high CER index) according to the median CER index in men and women (i.e., 13.71 and $12.06 \mathrm{mg} \cdot \mathrm{kg}^{-1} \cdot$ day $^{-1}$, respectively). Mortality and intracranial hemorrhage rates after CF-iLVAD implantation were significantly higher in the low than high CER index group (mortality $12.3 \%$ vs. $1.4 \%[P<0.01]$; intracranial hemorrhage $23.3 \%$ vs. $8.1 \%[P=0.01]$ ). Multivariate Cox proportional hazard models revealed that a low CER index was an independent predictor of intracranial hemorrhage in patients receiving a CF-iLVAD (hazard ratio 3.63; 95\% confidence interval 1.43-9.24; $\mathrm{P}<0.01$ ).
\end{abstract}

Conclusions: A low preoperative CER index is an independent, non-invasive predictor of intracranial hemorrhage after CF-iLVAD implantation.

Key Words: Creatinine excretion rate index; Heart failure; Intracranial hemorrhage; Sarcopenia

$\mathbf{P}$ atients with advanced (Stage D) heart failure (HF) have a poor prognosis, with annual mortality rates over $50 \%$ and limited medical treatment options. ${ }^{1}$ Continuous-flow implantable left ventricular assist devices (CF-iLVAD) have led to significant improvements in the survival of these patients, and are increasingly becoming an accepted treatment option. ${ }^{2,3}$ Although technological advances and clinical experience in this field have improved survival over time, ${ }^{4}$ numerous serious adverse events after CF-iLVAD implantation still occur. Cerebrovascular accidents (CVAs) are serious adverse events after $\mathrm{CF}$ -
iLVAD implantation that lead to significant morbidity and mortality. ${ }^{5}$

A loss of skeletal muscle mass, known as sarcopenia, is a frequent comorbidity among patients with $\mathrm{HF}$ and contributes to reduced exercise capacity and frailty. ${ }^{6}$ Sarcopenia is also associated with increased mortality independent of age or other clinical variables in various cardiovascular diseases, including HF. ${ }^{7-10}$ It was recently demonstrated that preoperative pectoralis muscle mass and attenuation by computed tomography (CT) were associated with mortality and increased length of hospitalization in patients with a

Received October 18, 2019; revised manuscript received March 1, 2020; accepted March 5, 2020; J-STAGE Advance Publication released online April 8, 2020 Time for primary review: 33 days

Department of Transplant Medicine (K.I., O.S., K.Y., N.Y., Y.S., E.A., H.M., K.K., S.N., T.W., M.Y., N.F.), Department of Preventive Medicine and Epidemiology (S.M., K.N.), Department of Cardiovascular Surgery (S.F., T.F., J.K.), National Cerebral and Cardiovascular Center, Suita; Department of Cardiovascular Medicine, Okayama University Graduate School of Medicine, Dentistry, and Pharmaceutical Sciences, Okayama (K.I., H.I.), Japan

Mailing address: Norihide Fukushima, MD, PhD, Department of Transplant Medicine, National Cerebral and Cardiovascular Center, 6-1 Kishibe-Shinmachi, Suita 564-0018, Japan. E-mail: nori@ncvc.go.jp

ISSN-1346-9843 All rights are reserved to the Japanese Circulation Society. For permissions, please e-mail: cj@j-circ.or.jp 


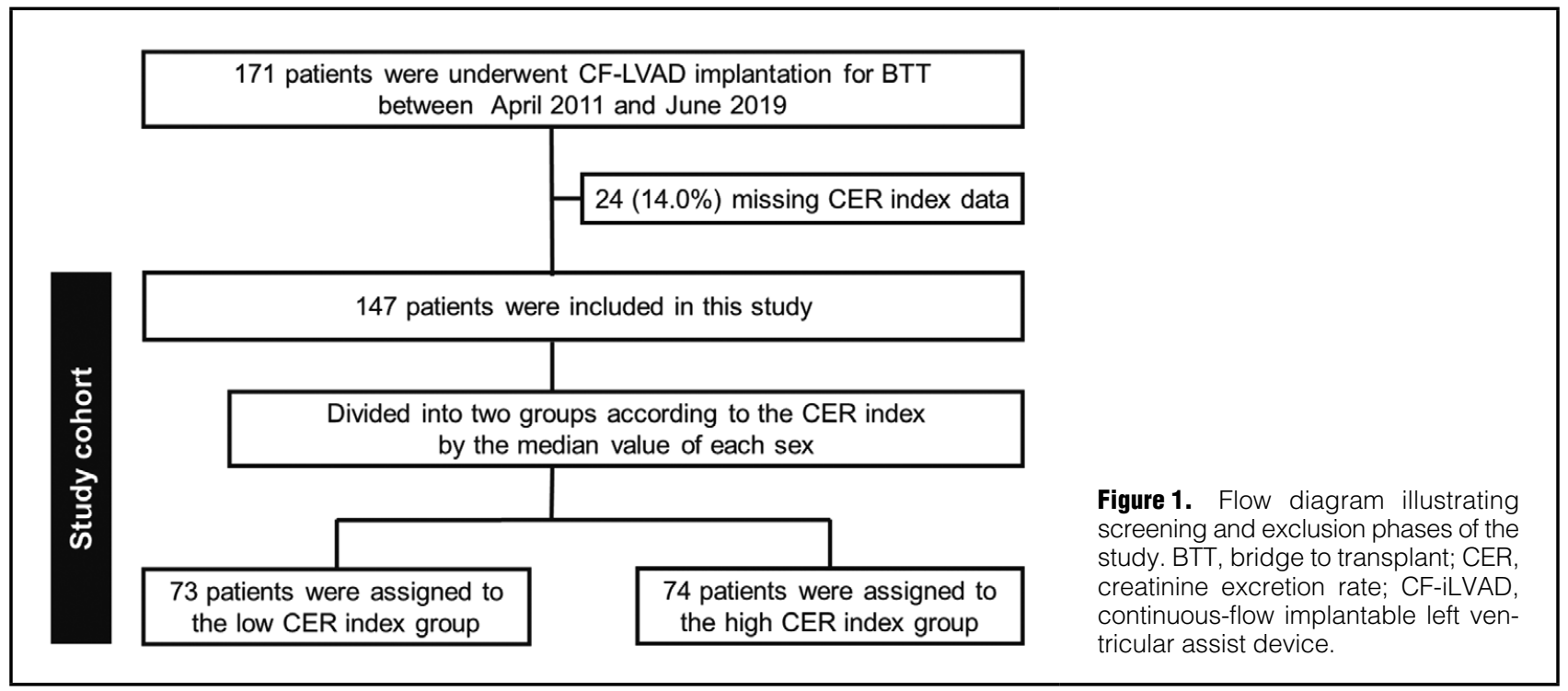

CF-iLVAD; ${ }^{11,12}$ however, the incidence of CVAs was not assessed in these studies. The creatinine excretion rate (CER) index, measured in 24-h urine samples, is an easily measured marker of total-body skeletal muscle mass ${ }^{13}$ that is considered a valid method even in patients with advanced renal failure, $\mathrm{HF}$, and wasting conditions, ${ }^{14-16}$ but its predictive capacity has not been investigated in patients with CF-iLVAD. The aim of the present study was to evaluate the prognostic effect of the preoperative CER index on mortality and CVA in patients with advanced HF and a CF-iLVAD.

\section{Methods}

\section{Study Population}

The present study was a retrospective single-center study. In all, 171 consecutive patients who underwent CF-iLVAD implantation were identified from a retrospective review of the National Cerebral and Cardiovascular Center database from April 2011 to June 2019. Of these patients, those for whom 24-h urine samples were collected within 3 months prior to CF-iLVAD implantation were included in the present analysis; 24-h urine samples were not collected for 24 patients and they were excluded from the study, leaving a final cohort of 147 eligible patients (Figure 1). The devices implanted in the patients included the HeartMate II $(n=104)$, HeartWare HVAD $(n=13)$, Jarvik $2000(n=12)$, EVAHEART $(n=11)$, and DuraHeart $(n=7)$. The median interval between 24-h urine collection and CF-iLVAD implantation was 8 days (interquartile range [IQR] 3-16 days).

In Japan, only patients $<65$ years of age can be listed as heart transplant candidates and CF-iLVAD have been approved by the National Insurance System as temporary devices for bridge to transplantation (BTT). For these reasons, patients who are not on the Japanese heart transplantation waiting list but require immediate mechanical circulatory support undergo paracorporeal left ventricular assist device (LVAD) implantation prior to CF-iLVAD implantation; however, once they have received approval for heart transplantation listing, these patients can undergo CF-iLVAD implantation (bridge to bridge; BTB).
This study was approved by the National Cerebral and Cardiovascular Center Institutional Review Board (IRB No. M29-139-2) and because of the nature of the study, the need for consent was waived.

\section{CER Index}

Urine creatinine was measured using the Roche Cobas 6000 Analyzer c501 module (Roche Diagnostics, Basel, Switzerland). The volume of urine collected over $24 \mathrm{~h}$ was recorded and the CER index $\left(\mathrm{mg} \cdot \mathrm{kg}^{-1} \cdot \mathrm{day}^{-1}\right)$ was calculated using the following formula:

$\mathrm{CER}$ index $=[\mathrm{Cr}]$ urine $\times 24-\mathrm{h}$ urine volume/body weight

where $[\mathrm{Cr}]$ urine is the urine creatinine concentration $(\mathrm{mg} / \mathrm{mL})$, urine volume was measured in milligrams per day, and body weight was measured in kilograms.

\section{Outcomes and Covariates}

The primary study outcomes were mortality and CVA. Other adverse events were evaluated, including major infections and major bleeding episodes, which were defined according to the Interagency Registry for Mechanically Assisted Circulatory Support (INTERMACS) adverse event criteria. ${ }^{17}$ CVA was defined as intracranial hemorrhage and ischemic stroke. Intracranial hemorrhage included subarachnoid hemorrhage, intracerebral hemorrhage, intraventricular hemorrhage, and subdural hematoma. Transient ischemic attacks and ischemic strokes, including ischemic strokes with hemorrhagic conversion, were grouped together as "ischemic strokes". All patients with a diagnosis of stroke were evaluated by a board-certified vascular neurologist and underwent CT scan studies. Magnetic resonance imaging (MRI) was not performed because of the incompatibility of CF-iLVADs with MRI.

Information for the following demographic and clinical covariates is available in the National Cerebral and Cardiovascular Center Database, which was updated through a manual chart review: age, sex, underlying diseases, history of hypertension, history of diabetes, history of atrial fibrillation, BTT status, INTERMACS profile, BTB, model of CF-iLVAD implanted, pre-LVAD medication, hemodynamics, echocardiographic parameters, and blood tests. 


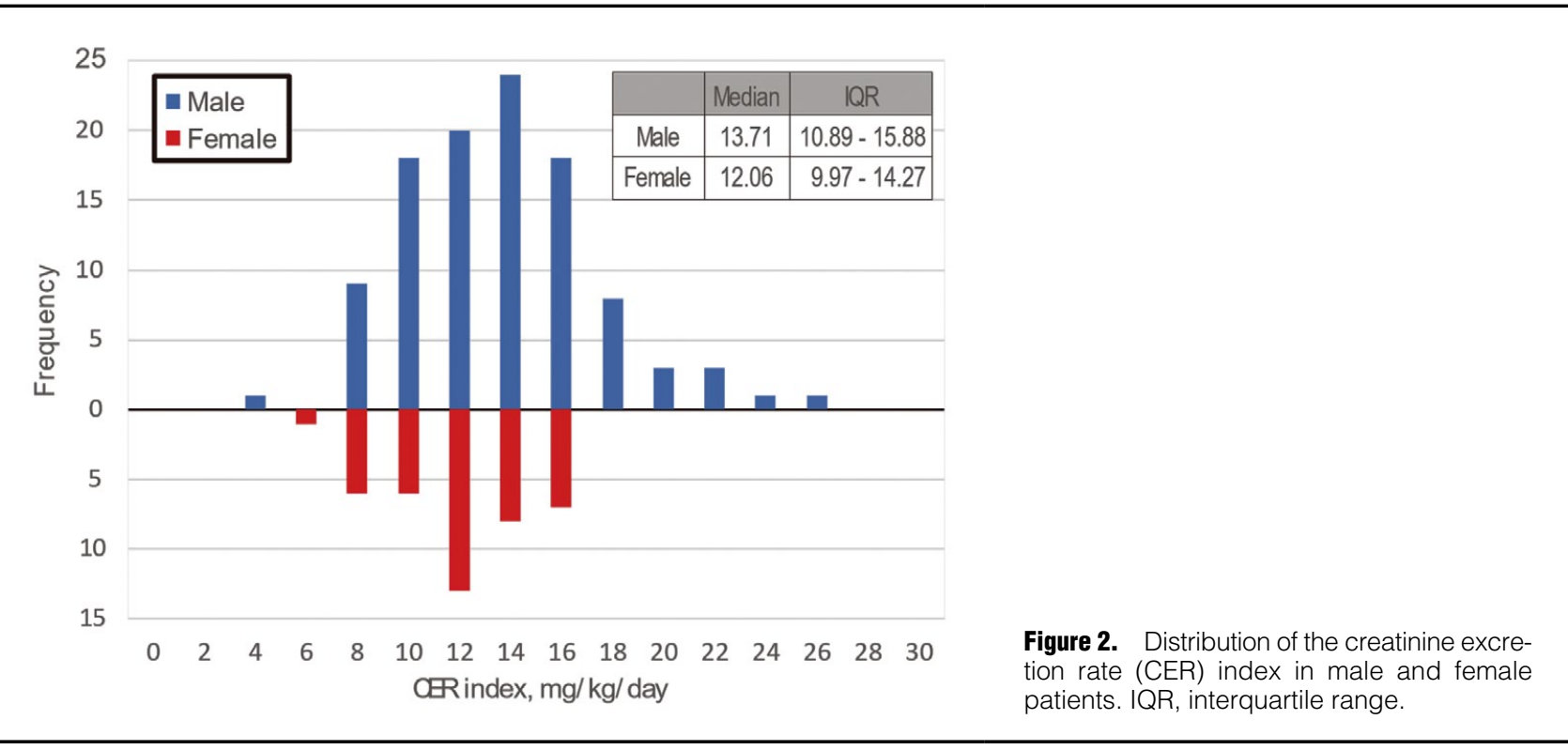

A

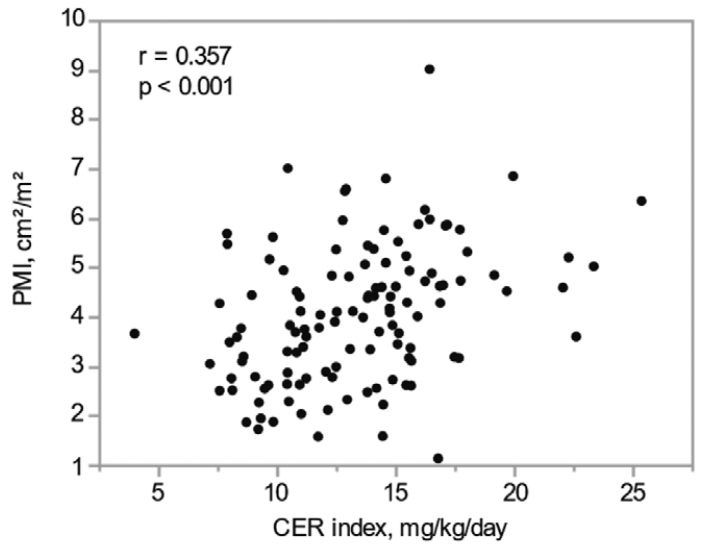

C

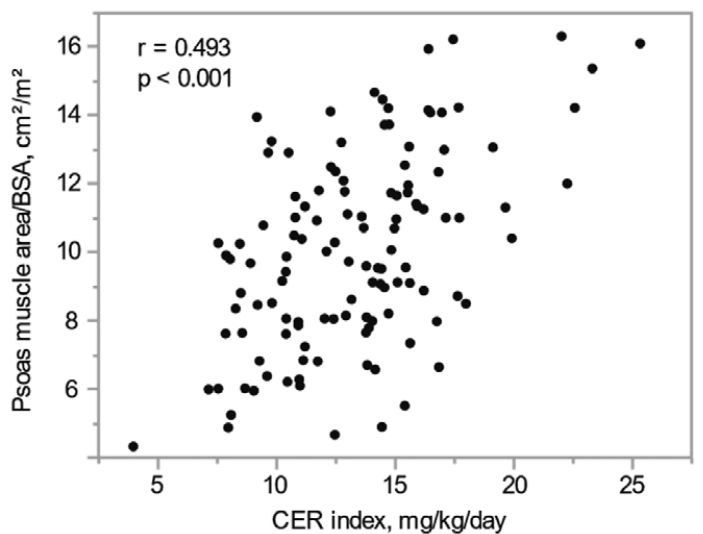

B

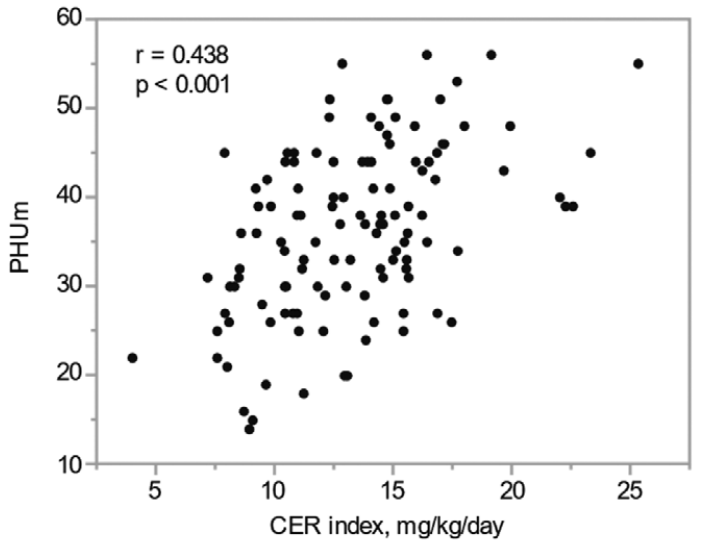

D

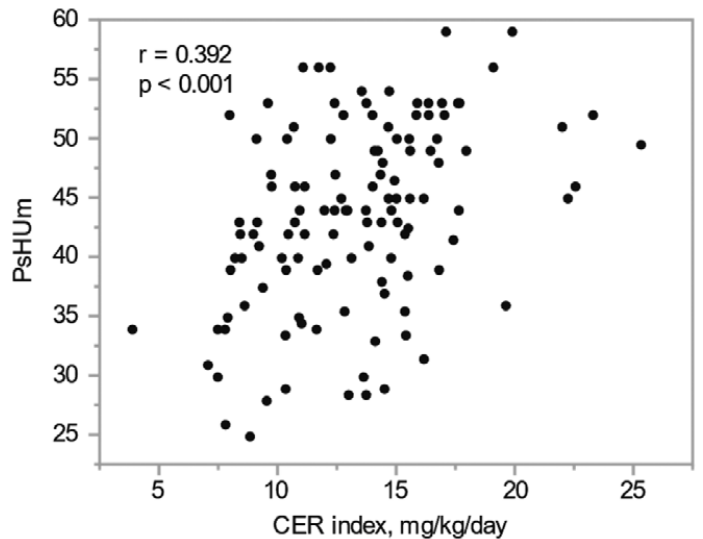

Figure 3. Correlation between the creatinine excretion rate (CER) index and other muscle mass markers, namely $(\mathbf{A})$ pectoralis muscle index (PMI), (B) pectoralis muscle mean Hounsfield unit (PHUm), (C) psoas muscle area/body surface area (BSA) ratio, and (D) psoas muscle mean Hounsfield unit (PsHUm). 


\begin{tabular}{|c|c|c|c|}
\hline & $\begin{array}{l}\text { Low CER index } \\
\qquad(n=73)\end{array}$ & $\begin{array}{l}\text { High CER index } \\
\qquad(n=74)\end{array}$ & P-value \\
\hline Age (years) & $44 \pm 13$ & $43 \pm 12$ & 0.667 \\
\hline Male sex & $53(73)$ & $53(72)$ & 1.000 \\
\hline Body height $(\mathrm{cm})$ & $167 \pm 9$ & $166 \pm 8$ & 0.885 \\
\hline Body weight (kg) & $61 \pm 14$ & $58 \pm 13$ & 0.107 \\
\hline Ischemic etiology & $10(14)$ & $11(15)$ & 1.000 \\
\hline Hypertension & $10(14)$ & $9(12)$ & 0.811 \\
\hline Diabetes & $22(30)$ & $21(28)$ & 0.857 \\
\hline Dyslipidemia & $25(34)$ & $27(36)$ & 0.863 \\
\hline Smoking & $42(58)$ & $38(51)$ & 0.509 \\
\hline Atrial fibrillation & $28(38)$ & $17(23)$ & 0.043 \\
\hline History of ICH & $3(4)$ & $1(1)$ & 0.366 \\
\hline History of ischemic stroke & $10(14)$ & $7(9)$ & 0.451 \\
\hline History of heart failure (days) & $1,673[288-3,401]$ & $1,248[378-2,784]$ & 0.409 \\
\hline Bridge to bridge & $29(40)$ & $12(16)$ & 0.002 \\
\hline INTERMACS profile & & & 0.008 \\
\hline 1 & $29(40)$ & $14(19)$ & \\
\hline 2 & $5(7)$ & $15(20)$ & \\
\hline 3 & $33(45)$ & $41(55)$ & \\
\hline $4-$ & $6(8)$ & $4(5)$ & \\
\hline iLVAD model & & & 0.598 \\
\hline HeartMate II & $48(66)$ & $56(76)$ & \\
\hline HeartWare HVAD & $9(12)$ & $4(5)$ & \\
\hline Jarvik 2000 & $6(8)$ & $6(8)$ & \\
\hline EVAHEART & $6(8)$ & $5(7)$ & \\
\hline DuraHeart & $4(6)$ & $3(4)$ & \\
\hline \multicolumn{4}{|l|}{ Medications } \\
\hline ACEI or ARB & $53(73)$ & $58(78)$ & 0.448 \\
\hline$\beta$-blockers & $60(82)$ & $61(82)$ & 1.000 \\
\hline MRAs & $65(89)$ & $63(85)$ & 0.624 \\
\hline
\end{tabular}

Patients were divided into 2 groups (low and high creatinine excretion rate [CER] index) according to the median CER index in men and women (i.e., 13.71 and $12.06 \mathrm{mg} \cdot \mathrm{kg}^{-1}$. day ${ }^{-1}$, respectively). Data are given as the mean $\pm \mathrm{SD}$, $\mathrm{n}(\%)$, or median [interquartile range]. ACEI, angiotensin-converting enzyme inhibitor; ARB, angiotensin receptor blocker; ICH, intracranial hemorrhage; iLVAD, implantable left ventricular assist device; INTERMACS, Interagency Registry for Mechanically Assisted Circulatory Support; MRAs, mineralocorticoid receptor antagonists.

The most recent hemodynamic, echocardiographic, and blood test data before CF-iLVAD implantation were used in this study. The median time from preoperative right heart catheter, echocardiography, and blood tests to CFiLVAD implantation was 13 days (IQR 4-28 days), 9 days (IQR 3-18 days), and 0 days (IQR $0-1$ days), respectively.

Muscle mass assessments by CT scans, including the pectoralis muscle index (PMI), pectoralis muscle mean Hounsfield unit (PHUm), psoas muscle area per body surface area (PsMA/BSA), and psoas muscle mean Hounsfield unit (PsHUm), were performed using methods described previously11,12 and the most recent preoperative plain CT scan before CF-iLVAD implantation. The median time from the preoperative CT scan to CF-iLVAD implantation was 14 days (IQR 5-32 days).

\section{Statistical Analysis}

Baseline characteristics of the study population are described as the mean $( \pm \mathrm{SD})$ or median (IQR) for continuous variables as appropriate, and as counts (percentages) for categorical variables. For continuous data, groups were compared using Student's t-test or the Wilcoxon rank-sum test on the basis of data distribution. All categorical variables were compared using Pearson's $\chi^{2}$ test.

To assess the effect of preoperative CER index on mortality and CVA, Kaplan-Meier survival analyses were performed. Mortality and CVA between groups were compared using the log-rank test. Because heart transplantation and device explantation for myocardial recovery were competing risks in this analysis, patients were censored at the time of transplantation or device explantation for myocardial recovery.

To assess the adjusted effect of preoperative CER index on intracranial hemorrhage, multivariate Cox proportional analyses were performed. Prespecified potential confounders of the relationship between CER index and intracranial hemorrhage, namely age at CF-iLVAD implantation, sex, body weight, ischemic etiology, hypertension, diabetes, smoking, history of intracranial hemorrhage, history of ischemic stroke, history of atrial fibrillation, BTB, INTERMACS profile, serum albumin, creatinine concentration, B-type natriuretic peptide, C-reactive protein, left ventricle diastolic dimension, and right atrial pressure prior to CF-iLVAD implantation were tested for significance in 


\begin{tabular}{|c|c|c|c|}
\hline & $\begin{array}{l}\text { Low CER index } \\
\qquad(n=73)\end{array}$ & $\begin{array}{l}\text { High CER index } \\
\qquad(n=74)\end{array}$ & P-value \\
\hline \multicolumn{4}{|l|}{ Laboratory values } \\
\hline Albumin (g/dL) & $3.6 \pm 0.7$ & $3.8 \pm 0.5$ & 0.136 \\
\hline Total bilirubin (mg/dL) & 0.9 [0.6-1.3] & $0.8[0.6-1.2]$ & 0.407 \\
\hline Creatinine (mg/dL) & $0.85[0.66-1.18]$ & $0.94[0.75-1.18]$ & 0.273 \\
\hline eGFR (mL/min/1.73 m²) & $91[64-128]$ & $85[59-107]$ & 0.219 \\
\hline $\mathrm{BNP}(\mathrm{pg} / \mathrm{mL})$ & 496 [269-808] & 428 [263-836] & 0.493 \\
\hline CRP (mg/dL) & $0.56[0.08-2.48]$ & $0.25[0.07-1.02]$ & 0.092 \\
\hline \multicolumn{4}{|l|}{ Echocardiographic parameters } \\
\hline LVDd (mm) & $65 \pm 16$ & $70 \pm 13$ & 0.022 \\
\hline Ejection fraction (\%) & $18 \pm 8$ & $17 \pm 8$ & 0.586 \\
\hline $\operatorname{LAD}(\mathrm{mm})$ & $43 \pm 12$ & $44 \pm 9$ & 0.672 \\
\hline \multicolumn{4}{|l|}{ Hemodynamic parameters } \\
\hline Heart rate (beats/min) & $83 \pm 19$ & $82 \pm 18$ & 0.759 \\
\hline Mean BP $(\mathrm{mmHg})$ & $72 \pm 11$ & $69 \pm 11$ & 0.124 \\
\hline PCWP $(\mathrm{mmHg})$ & $20 \pm 10$ & $19 \pm 10$ & 0.589 \\
\hline Mean PAP $(\mathrm{mmHg})$ & $29 \pm 12$ & $28 \pm 12$ & 0.451 \\
\hline $\mathrm{RAP}(\mathrm{mmHg})$ & $10 \pm 5$ & $7 \pm 4$ & $<0.001$ \\
\hline Cardiac index $\left(\mathrm{L} \cdot \mathrm{min}^{-1} \cdot \mathrm{m}^{-2}\right)$ & $2.15 \pm 0.69$ & $1.99 \pm 0.50$ & 0.123 \\
\hline \multicolumn{4}{|l|}{ CT parameters } \\
\hline $\mathrm{PMI}\left(\mathrm{cm}^{2} / \mathrm{m}^{2}\right)$ & $3.72 \pm 1.28$ & $4.35 \pm 1.35$ & 0.004 \\
\hline PHUm & $34 \pm 9$ & $40 \pm 9$ & $<0.001$ \\
\hline PsMA/BSA $\left(\mathrm{cm}^{2} / \mathrm{m}^{2}\right)$ & $9.05 \pm 2.45$ & $10.36 \pm 3.04$ & 0.005 \\
\hline PsHUm & $41 \pm 8$ & $46 \pm 7$ & $<0.001$ \\
\hline \multicolumn{4}{|l|}{ Urinalysis values } \\
\hline CER (mg/day) & 639 [522-756] & $887[732-1,058]$ & $<0.001$ \\
\hline CER index $\left(\mathrm{mg} \cdot \mathrm{kg}^{-1} \cdot \mathrm{day}^{-1}\right)$ & $10.76[9.08-11.97]$ & $15.39[14.13-16.82]$ & $<0.001$ \\
\hline
\end{tabular}

Patients were divided into 2 groups (low and high creatinine excretion rate [CER] index) according to the median CER index in men and women (i.e., 13.71 and $12.06 \mathrm{mg} \cdot \mathrm{kg}^{-1}$. day-1, respectively). Data are given as the mean $\pm S D$ or median [interquartile range]. BNP, B-type natriuretic peptide; BP, blood pressure; BSA, body surface area; CRP, C-reactive protein; $C T$, computed tomography; eGFR, estimated glomerular filtration rate; $L A D$, left anterior descending coronary artery; LVDd, left ventricular diastolic dimension; PAP, pulmonary arterial pressure; PCWP, pulmonary capillary wedge pressure; PHUm, pectoralis muscle mean Hounsfield unit; PMI, pectoralis muscle index; PsHUm, psoas muscle mean Hounsfield unit; PsMA, psoas muscle area; RAP, right atrial pressure.

a univariate analysis. Then, these factors were incorporated in a forward and backward stepwise manner using the Wald test for significance and a P-value of $<0.05$ to obtain the final adjusted model. The adjusted effect of preoperative CER index on intracranial hemorrhage was assessed in the final model.

For all analyses, $\mathrm{P}<0.05$ was considered significant. All statistical analyses were conducted using JMP version 9 (SAS Institute, Cary, NC, USA) and SAS version 9.4 (SAS Institute).

\section{Results}

\section{Baseline Characteristics According to CER Index}

The distribution of CER indices for the 24-h urine collections are shown in Figure 2; in men, the median CER index was $13.71 \mathrm{mg} \cdot \mathrm{kg}^{-1} \cdot \mathrm{day}^{-1}\left(\mathrm{IQR} 10.89-15.88 \mathrm{mg} \cdot \mathrm{kg}^{-1} \cdot \mathrm{day}^{-1}\right)$, whereas in women it was $12.06 \mathrm{mg} \cdot \mathrm{kg}^{-1} \cdot \mathrm{day}^{-1}$ (IQR 9.97$\left.14.27 \mathrm{mg} \cdot \mathrm{kg}^{-1} \cdot \mathrm{day}^{-1}\right)$. The CER index was significantly associated with previously muscle mass assessments by $\mathrm{CT}$, namely PMI, PHUm, PsMA/BSA, and PsHUm (Figure 3). Because the CER index has been reported to be affected by sex, the study population was divided into 2 groups (low and high CER index groups) according to the median
CER index in men and women (i.e., 13.71 and $12.06 \mathrm{mg}$. $\mathrm{kg}^{-1} \cdot \mathrm{day}^{-1}$, respectively). Consequently, 73 and 74 patients were assigned to the low and high CER index groups, respectively. The clinical characteristics of the 2 groups are presented in Tables 1 and 2. Patients in the low CER index group were more likely to be BTB patients and INTERMACS Profile 1 and to have atrial fibrillation, smaller left ventricular diastolic diameter, and higher right atrial pressure. The median (IQR) CER indices in the low and high groups were 10.76 (9.08-11.97) and 15.39 (14.13-16.82) $\mathrm{mg} \cdot \mathrm{kg}^{-1} \cdot \mathrm{day}^{-1}$, respectively. Muscle mass parameters assessed using CT (i.e., PMI, PHUm, PsMA/ BSA, and PsHUm) were significantly lower in the low than high CER group.

\section{Clinical Outcomes by CER Index}

Clinical outcomes are presented in Table 3 and Figure 4. Over a median follow-up of 2.3 years (IQR 1.1-3.1 years), there were $10(6.8 \%)$ deaths and $43(29.3 \%)$ CVAs (ischemic stroke, $n=20$; intracranial hemorrhage, $n=23$ ). There was no significant difference in follow-up period between the low and high CER index groups (median [IQR] 834 [363$1,124]$ vs. 827 [401-1,186] days, respectively; $\mathrm{P}=0.60$ ). The incidence of mortality and intracranial hemorrhage was 
Table 3. Clinical Outcomes of the Low and High Creatinine Excretion Rate Index Groups

\begin{tabular}{lccc} 
& $\mathbf{( n = 7 3 )}$ & $(\mathbf{n}=\mathbf{7 4})$ & P-value \\
Follow-up period (days) & $834[363-1,124]$ & $827[401-1,186]$ & 0.601 \\
Clinical outcomes & & & \\
Death & $9(12)$ & $1(1)$ & 0.009 \\
Cerebrovascular accident & $27(37)$ & $16(22)$ & 0.047 \\
ICH & $17(23)$ & $6(8)$ & 0.013 \\
Ischemic stroke & $10(14)$ & $10(14)$ & 1.000 \\
Major infection & $36(49)$ & $36(49)$ & 1.000 \\
Major bleeding & $37(51)$ & $34(46)$ & 0.622 \\
Transplant & $20(27)$ & $25(34)$ & 0.475 \\
Explantation for recovery & $0(0)$ & $0(0)$ & - \\
\hline
\end{tabular}

Patients were divided into 2 groups (low and high CER index) according to the median CER index in men and women (i.e., 13.71 and $12.06 \mathrm{mg} \cdot \mathrm{kg}^{-1} \cdot$ day $^{-1}$, respectively). Data are given as the median [interquartile range] or $\mathrm{n}$ (\%). Abbreviations as in Table 1.

A
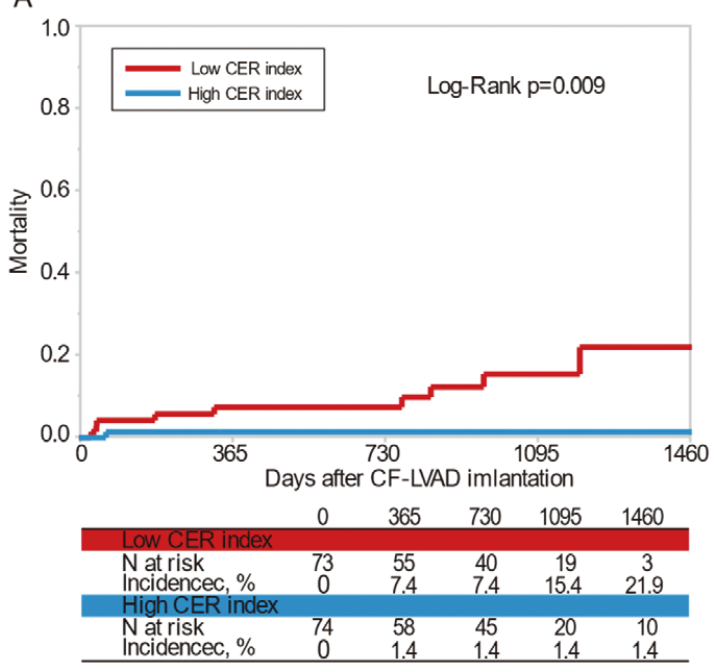

C
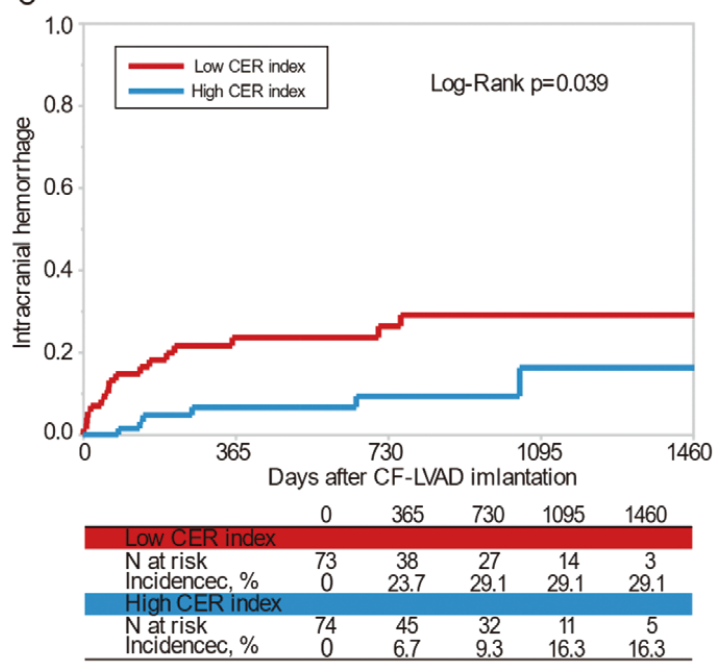

B

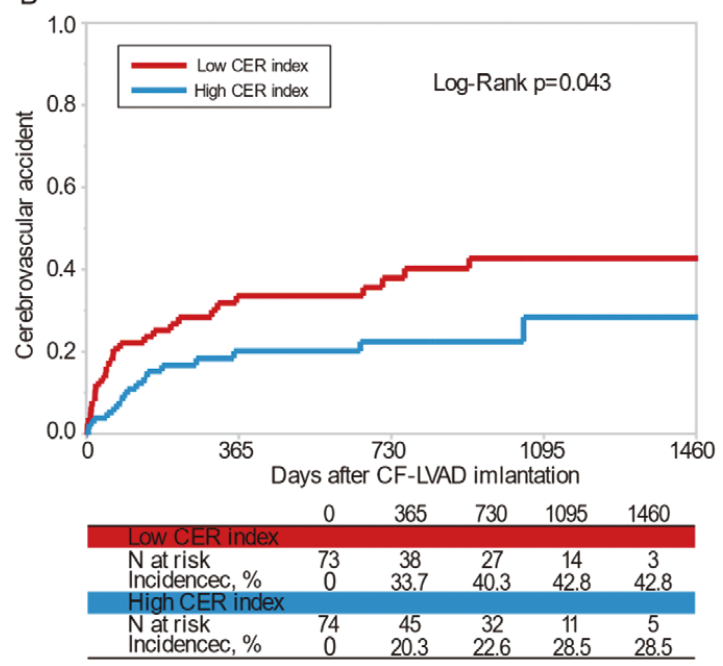

D

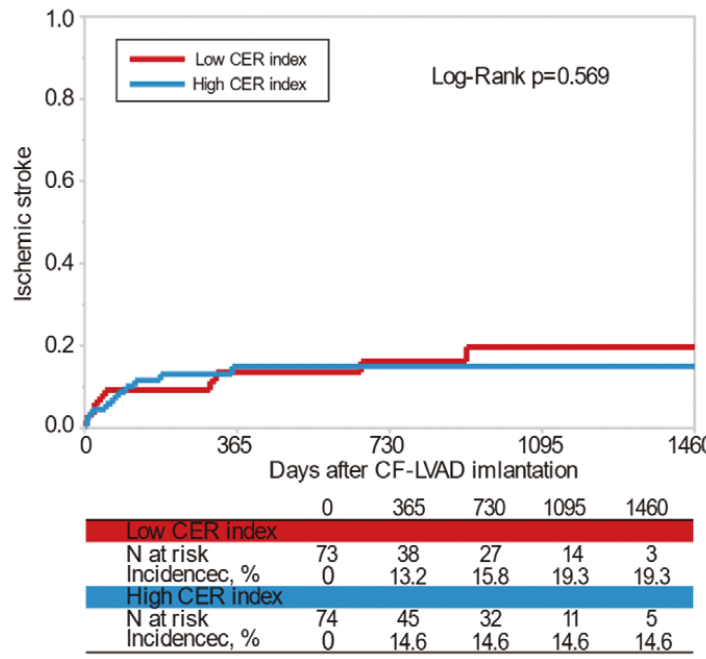

Figure 4. Kaplan-Meier estimates of clinical events, namely $(\mathbf{A})$ mortality, $(\mathbf{B})$ cerebrovascular accidents, $(\mathbf{C})$ intracranial hemorrhage, and (D) ischemic stroke, after continuous-flow implantable left ventricular assist device (CF-iLVAD) implantation. Patients were divided into 2 groups (low and high creatinine excretion rate [CER] index) according to the median CER index in men and women (i.e., 13.71 and $12.06 \mathrm{mg} \cdot \mathrm{kg}^{-1} \cdot$ day $^{-1}$, respectively). 


\begin{tabular}{|c|c|c|c|c|c|c|}
\hline & Univariate HR & $95 \% \mathrm{Cl}$ & P-value & Adjusted HR & $95 \% \mathrm{Cl}$ & P-value \\
\hline Age & 0.98 & $0.95-1.01$ & 0.157 & - & - & - \\
\hline Male sex & 0.48 & $0.21-1.09$ & 0.078 & - & - & - \\
\hline Body height & 0.96 & $0.92-1.01$ & 0.127 & - & - & - \\
\hline Body weight & 0.96 & $0.93-1.00$ & 0.026 & 0.96 & $0.92-0.99$ & 0.011 \\
\hline Ischemic etiology & 0.64 & $0.15-2.75$ & 0.551 & - & - & - \\
\hline Hypertension & 0.36 & $0.05-2.70$ & 0.363 & - & - & - \\
\hline Diabetes & 0.72 & $0.27-1.94$ & 0.514 & - & - & - \\
\hline Smoking & 0.53 & $0.23-1.23$ & 0.141 & - & - & - \\
\hline Atrial fibrillation & 1.21 & $0.51-2.86$ & 0.665 & - & - & - \\
\hline History of ICH & 1.82 & $0.24-13.49$ & 0.560 & - & - & - \\
\hline History of ischemic stroke & 0.37 & $0.05-2.73$ & 0.328 & - & - & - \\
\hline Bridge to bridge & 1.79 & $0.75-4.24$ & 0.187 & - & - & - \\
\hline INTERMACS profile & 0.94 & $0.61-1.44$ & 0.940 & - & - & - \\
\hline Albumin & 0.59 & $0.30-1.19$ & 0.141 & - & - & - \\
\hline Creatinine & 0.41 & $0.11-1.53$ & 0.184 & - & - & - \\
\hline BNP (per 100pg/mL) & 1.01 & $0.96-1.06$ & 0.653 & - & - & - \\
\hline CRP & 1.06 & $0.95-1.18$ & 0.282 & - & - & - \\
\hline LVDd & 0.98 & $0.95-1.01$ & 0.118 & - & - & - \\
\hline RAP & 1.08 & $1.01-1.15$ & 0.023 & - & - & - \\
\hline Low CER index & 3.16 & $1.25-8.03$ & 0.016 & 3.63 & $1.43-9.24$ & 0.007 \\
\hline
\end{tabular}

$\mathrm{Cl}$, confidence interval; $\mathrm{HR}$, hazard ratio. Other abbreviations as in Tables 1,2.

significantly higher in the low than high CER index group $(12.3 \%$ vs. $1.4 \%[\mathrm{P}<0.01]$ and $23.3 \%$ vs. $8.1 \%[\mathrm{P}=0.01]$, respectively). There were no significant differences between the groups in terms of the incidence of ischemic stroke, major infection, major bleeding, and heart transplantation. None of the patients in this cohort required explantation of CF-iLVAD for myocardial recovery.

\section{Predictors of Intracranial Hemorrhage After CF-iLVAD Implantation}

Ten deaths occurred in the study cohort, and this number was considered too small for multivariate analysis. Therefore, predictors of clinical outcomes were only assessed for patients experiencing intracranial hemorrhage. In univariate analysis (Table 4), a low CER index was a significant predictor of intracranial hemorrhage (hazard ratio [HR] 3.16 ; 95\% confidence interval $[\mathrm{CI}] 1.25-8.03 ; \mathrm{P}=0.02$ ). Similarly, in the multivariate Cox proportional hazard model, a low CER index was a significant independent predictor of intracranial hemorrhage (HR 3.63; 95\% CI $1.43-9.24 ; \mathrm{P}<0.01)$.

\section{Discussion}

In this study we analyzed the effect of the CER index, a maker of sarcopenia, before implantation of a CF-iLVAD on clinical outcomes after implantation, including mortality and major CF-iLVAD-related adverse events such as intracranial hemorrhage, ischemic stroke, major infection, and major bleeding. The CER index was found to be significantly associated with pectoralis muscle size and attenuation, indicating that the CER index reflects skeletal muscle quantity and quality. Mortality was higher among patients with a low than high CER index. Furthermore, a low CER index was an independent predictor for intracranial hemorrhage after CF-iLVAD implantation.
Sarcopenia is a frequent comorbidity among patients with $\mathrm{HF}^{6}$ and has been reported to be associated with various adverse clinical outcomes. ${ }^{7,9,11}$ Pectoralis muscle size and attenuation, which are markers of skeletal muscle quantity and quality, have been shown recently to be independent predictors of mortality after CF-iLVAD implantation. ${ }^{12}$ Creatinine, a byproduct generated from muscle metabolism filtered through the kidneys and excreted in the urine, has been recognized as a surrogate for individual skeletal muscle mass and could be a predictor of mortality and adverse events in various clinical settings. ter Maaten et al recently reported that morning spot urine creatinine concentration is an independent predictor of mortality or hospitalization in HF patients. ${ }^{18}$ Furthermore, these authors also demonstrated that a low CER was significantly associated with an increased risk of adverse outcomes, such as mortality, heart transplantation, myocardial infarction, and hospitalization, in systolic HF patients. ${ }^{15}$

Given this evidence, we assessed the clinical significance of CER, an established marker of skeletal muscle mass, in our patient population with advanced HF on CF-iLVAD support. In this study we used the CER index instead of the CER itself to accurately evaluate excreted creatinine independent of body size. Furthermore, the patient cohort was divided by median values of the CER index for each sex separately, which enables accurate evaluation of excreted creatinine independent of sex. Forni Ogna et al reported that mean CER indices in the general Swiss population were $17.06 \pm 3.62$ and $13.35 \pm 3.36 \mathrm{mg} \cdot \mathrm{kg}^{-1} \cdot \mathrm{day}^{-1}$ in men and women, respectively. ${ }^{19}$ However, the median (IQR) values of CER indices in men and women in the present study were $13.71(10.89-15.88)$ and 12.06 (9.9714.27) $\mathrm{mg} \cdot \mathrm{kg}^{-1} \cdot \mathrm{day}^{-1}$, respectively. The lower CER index values in our study cohort suggest a prevalence of sarcopenia in our patient population with advanced HF eligible for CF-iLVAD implantation. 
With regard to mechanisms, we do not have enough original data to explain why preoperative sarcopenia or frailty may be associated with hemorrhagic complications, especially intracranial hemorrhage, in patients with CFiLVAD. However, sarcopenia or frailty may be associated with cerebrocardiovascular adverse events through increased arterial stiffness. Low skeletal muscle mass has been found to be significantly associated with increased arterial stiffness in a general elderly population. ${ }^{20}$ Arterial stiffness, usually evaluated by measuring arterial pulse wave velocity as a surrogate marker of endothelial function and atherosclerosis, increases with aging and is associated with various cerebrocardiovascular, events including cerebral microbleeds. ${ }^{21}$ Tanaka et al reported that relative skeletal muscle mass index is independently associated with brachial-ankle pulse wave velocity, a marker of arterial stiffness, in postmenopausal women with type 2 diabetes mellitus after adjusting for age, duration of type 2 diabetes mellitus, systolic blood pressure, body mass index, HbA1c, creatinine, low-density lipoprotein, uric acid, and antihypertensive medication, ${ }^{22}$ indicating that sarcopenia is associated with arterial stiffness regardless of atherosclerosis-related comorbidities. Because implantation of CF-iLVAD attenuates peripheral endothelial function, complications of sarcopenia or frailty in patients with advanced HF before CF-iLVAD implantation may exaggerate the attenuation of endothelial function. ${ }^{23}$ In addition, Chung et al provided direct evidence of an association between physical frailty and cerebral microbleeds in a young Asian population, ${ }^{24}$ and Yoshioka et al reported that cerebral microbleeds evaluated after LVAD explantation were associated with intracranial hemorrhage in patients with CF-iLVAD. ${ }^{25}$ The administration of anticoagulants and/or antiplatelet agents may exaggerate the development of intracranial hemorrhage in patients with cerebral microbleeds, ${ }^{26}$ and sarcopenia or frailty may be associated with cerebral microbleeds following intracranial hemorrhage via mechanisms linked to endothelial dysfunction. Acquired von Willebrand syndrome in patients with CF-iLVAD and BTB may also have an effect on the development of intracranial hemorrhage.

To the best of our knowledge, the present study is the first to demonstrate that sarcopenia could be a predictor of intracranial hemorrhage after CF-iLVAD implantation. This finding suggests that assessment of sarcopenia may provide novel information alongside conventional risk models to predict intracranial hemorrhage after CF-iLVAD implantation. Even though CF-iLVAD implantation may prevent progression of sarcopenia through hemodynamic improvement, sarcopenia before CF-iLVAD implantation may be a significant risk factor for intracranial hemorrhage after CF-iLVAD implantation. Therefore, preoperative assessment of nutritional status as well as sarcopenia, early CF-iLVAD implantation before patients are complicated with sarcopenia, and nutrition management before and after CF-iLVAD implantation may be beneficial in reducing intracranial hemorrhage after CF-iLVAD implantation. Further studies are warranted to elucidate the optimal management of these sarcopenia patients.

\section{Study Limitations}

First, the present study was a small retrospective singlecenter study. Although we used a Cox proportional hazard model to adjust for multivariate analyses, the sample size in this study was small. Therefore, to validate the findings from this study, a large-scale multicenter prospective study is recommended. Second, although the 24-h CER index is an established method for assessing skeletal muscle mass, CT or MRI studies are currently considered the gold standard. ${ }^{27}$ Nonetheless, we compared the CER index to pectoralis and psoas muscle volume in the present study, and not to other standard assessment methods, such as dual-energy X-ray absorptiometry. In addition, functional assessment of muscle performance (e.g., the 6-minute walk distance and peak oxygen consumption $\left[\mathrm{V}_{2}\right]$ in a cardiopulmonary exercise test) was not conducted because of the retrospective nature of the study, and such assessments are required for a diagnosis of sarcopenia, as defined by the European Working Groups on Sarcopenia in Older People. ${ }^{28}$ Moreover, we did not evaluate frailty using a common assessment method in this study, nor did we assess whether the CER index was correlated with a patient's frailty. Third, in this study we evaluated only preoperative and not postoperative factors (e.g., infection, anticoagulation level, and blood pressure). Fourth, we do not have enough original data to explain why sarcopenia was associated with intracranial hemorrhage. Further studies regarding this aspect are warranted.

\section{Conclusions}

A preoperative low CER index was an independent predictor of intracranial hemorrhage after CF-iLVAD implantation. This easily measured, repeatable assessment provides valuable prognostic information that is not available from standard preoperative assessments. Multicenter studies in larger and more diverse populations are needed to confirm these findings.

\section{Acknowledgments}

The authors gratefully acknowledge the work of past and present members of our center. The authors also thank Editage (www.editage. com) for English language editing.

\section{Sources of Funding}

This work was supported by the Japan Society for the Promotion of Science (KAKENHI Grant no. 19K17580).

\section{Conflict of Interest}

The authors have no conflicts of interest to declare.

\section{References}

1. Ahmad T, Patel CB, Milano CA, Rogers JG. When the heart runs out of heartbeats: Treatment options for refractory end-stage heart failure. Circulation 2012; 125: 2948-3055.

2. Rose EA, Gelijns AC, Moskowitz AJ, Heitjan DF, Stevenson LW, Dembitsky W, et al. Long-term use of a left ventricular assist device for end-stage heart failure. $N$ Engl J Med 2001; 345: $1435-1443$.

3. Estep JD, Starling RC, Horstmanshof DA, Milano CA, Selzman $\mathrm{CH}$, Shah KB, et al. Risk assessment and comparative effectiveness of left ventricular assist device and medical management in ambulatory heart failure patients: Results from the ROADMAP study. J Am Coll Cardiol 2015; 66: 1747-1761.

4. Jorde UP, Kushwaha SS, Tatooles AJ, Naka Y, Bhat G, Long JW, et al. Results of the destination therapy post-food and drug administration approval study with a continuous flow left ventricular assist device: A prospective study using the INTERMACS registry (Interagency Registry for Mechanically Assisted Circulatory Support). J Am Coll Cardiol 2014; 63: $1751-1757$.

5. Frontera JA, Starling R, Cho SM, Nowacki AS, Uchino K, Hussain MS, et al. Risk factors, mortality, and timing of ischemic 
and hemorrhagic stroke with left ventricular assist devices. $J$ Heart Lung Transplant 2017; 36: 673-683.

6. Fülster S, Tacke M, Sandek A, Ebner N, Tschöpe C, Doehner $\mathrm{W}$, et al. Muscle wasting in patients with chronic heart failure: Results from the Studies Investigating Co-Morbidities Aggravating Heart Failure (SICA-HF). Eur Heart J 2013; 34: 512-519.

7. Saji M, Lim DS, Ragosta M, LaPar DJ, Downs E, Ghanta RK, et al. Usefulness of psoas muscle area to predict mortality in patients undergoing transcatheter aortic valve replacement. $\mathrm{Am}$ J Cardiol 2016; 118: 251-257.

8. Yamada S, Kamiya K, Kono Y. Frailty may be a risk marker for adverse outcome in patients with congestive heart failure. ESC Heart Fail 2015; 2: 168-170.

9. Onoue Y, Izumiya Y, Hanatani S, Tanaka T, Yamamura S, Kimura $Y$, et al. A simple sarcopenia screening test predicts future adverse events in patients with heart failure. Int $J$ Cardiol 2016; 215: $301-306$.

10. Pulignano G, Del Sindaco D, Di Lenarda A, Alunni G, Senni M, Tarantini $\mathrm{L}$, et al. Incremental value of gait speed in predicting prognosis of older adults with heart failure insights from the IMAGE-HF Study. JACC Heart Fail 2016; 4: 289-298.

11. Heberton GA, Nassif M, Bierhals A, Novak E, LaRue SJ, Lima B, et al. Usefulness of psoas muscle area determined by computed tomography to predict mortality or prolonged length of hospital stay in patients undergoing left ventricular assist device implantation. Am J Cardiol 2016; 118: 1363-1367.

12. Teigen LM, John R, Kuchnia AJ, Nagel EM, Earthman CP, Kealhofer J, et al. Preoperative pectoralis muscle quantity and attenuation by computed tomography are novel and powerful predictors of mortality after left ventricular assist device implantation. Circ Heart Fail 2017; 10: e004069.

13. Wang ZM, Gallagher D, Nelson ME, Matthews DE, Heymsfield SB. Total-body skeletal muscle mass: Evaluation of 24-h urinary creatinine excretion by computerized axial tomography. Am J Clin Nutr 1996; 63: 863-869.

14. Beddhu S, Pappas LM, Ramkumar N, Samore M. Effects of body size and body composition on survival in hemodialysis patients. J Am Soc Nephrol 2003; 14: 2366-2372.

15. ter Maaten J, Damman K, Hillege HL, Bakker SS, Anker SD, Navis $G$, et al. Creatinine excretion rate, a marker of muscle mass, is related to clinical outcome in patients with chronic systolic heart failure. Clin Res Cardiol 2014; 103: 976-983.

16. Poortmans JR, Boisseau N, Moraine JJ, Moreno-Reyes R, Goldman S. Estimation of total-body skeletal muscle mass in children and adolescents. Med Sci Sports Exerc 2005; 37: 316.

17. Kirklin J, Naftel D, Pagani F, Kormos R, Stevenson L, Blume E, et al. Seventh INTERMACS annual report: 15,000 patients and counting. J Heart Lung Transplant 2015; 34: 1495-1504.

18. ter Maaten JM, Maggioni AP, Latini R, Masson S, Tognoni G, Tavazzi L, et al. Clinical and prognostic value of spot urinary creatinine in chronic heart failure: An analysis from GISSI-HF. Am Heart J 2017; 188: 189-195.

19. Forni Ogna V, Ogna A, Vuistiner P, Pruijm M, Ponte B, Ackermann $\mathrm{D}$, et al. New anthropometry-based age- and sex-specific reference values for urinary 24-hour creatinine excretion based on the adult Swiss population. BMC Med 2015; 13: 40.

20. Sampaio RA, Sewo Sampaio PY, Yamada M, Yukutake T, Uchida MC, Tsuboyama T, et al. Arterial stiffness is associated with low skeletal muscle mass in Japanese community-dwelling older adults. Geriatr Gerontol Int 2014; 14: 109-114.

21. Song TJ, Kim J, Lee HS, Nam CM, Nam HS, Kim YD, et al. Distribution of cerebral microbleeds determines their association with impaired kidney function. J Clin Neurol 2014; 10: 222-228.

22. Tanaka T, Kanazawa I, Sugimoto T. Reduced muscle mass and accumulation of visceral fat are independently associated with increased arterial stiffness in postmenopausal women with type 2 diabetes mellitus. Diabetes Res Clin Pract 2016; 122: 141 - 147.

23. Hasin T, Matsuzawa Y, Guddeti RR, Aoki T, Kwon TG, Schettle $\mathrm{S}$, et al. Attenuation in peripheral endothelial function after continuous flow left ventricular assist device therapy is associated with cardiovascular adverse events. Circ J 2015; 79: $770-777$.

24. Chung CP, Chou KH, Chen WT, Liu LK, Lee WJ, Chen LK, et al. Cerebral microbleeds are associated with physical frailty: A community-based study. Neurobiol Aging 2016; 44: 143-150.

25. Yoshioka D, Okazaki S, Toda K, Murase S, Saito S, Domae K, et al. Prevalence of cerebral microbleeds in patients with continuousflow left ventricular assist devices. J Am Heart Assoc 2017; 6: pii: $\mathrm{e} 005955$.

26. Wang Z, Soo Y, Mok V. Cerebral microbleeds: Is antithrombotic therapy safe to administer? Stroke 2014; 45: 2811-2817.

27. Cooper C, Fielding R, Visser M, van Loon LJ, Rolland Y, Orwoll E, et al. Tools in the assessment of sarcopenia. Calcif Tissue Int 2013; 93: 201-210.

28. Cruz-Jentoft AJ, Baeyens JP, Bauer JM, Boirie Y, Cederholm T, Landi F, et al. Sarcopenia: European consensus on definition and diagnosis, Report of the European Working Group on Sarcopenia in Older People. Age Ageing 2010; 39: 412-423. 